\title{
Erratum to: Thermal analysis and calorimetry in Central and Eastern Europe as a tool for solving diverse issues in different fields of science and applications
}

\author{
Romana Cerc Korošec ${ }^{1}$ - Andrei Rotaru ${ }^{2}$
}

Published online: 4 February 2017

(C) Akadémiai Kiadó, Budapest, Hungary 2017

Erratum to: J Therm Anal Calorim (2017)

127:15-19

DOI 10.1007/s10973-016-5894-8

Herewith we claim that the scientific title of the Guest CoEditors in the January 2017 issue of the Journal of Thermal Analysis and Calorimetry is "Doctor". Therefore, our names should be read as follows: Dr. Romana Cerc Korošec and Dr. Andrei Rotaru.

The online version of the original article can be found under doi:10.1007/s10973-016-5894-8.

Romana Cerc Korošec

romana.cerc-korosec@fkkt.uni-lj.si

Andrei Rotaru

andrei.rotaru@inflpr.ro

1 Faculty of Chemistry and Chemical Technology, University of Ljubljana, Ljubljana, Slovenia

2 INFLPR - National Institute for Laser, Plasma and Radiation Physics, Măgurele (Ilfov), Bucharest, Romania 